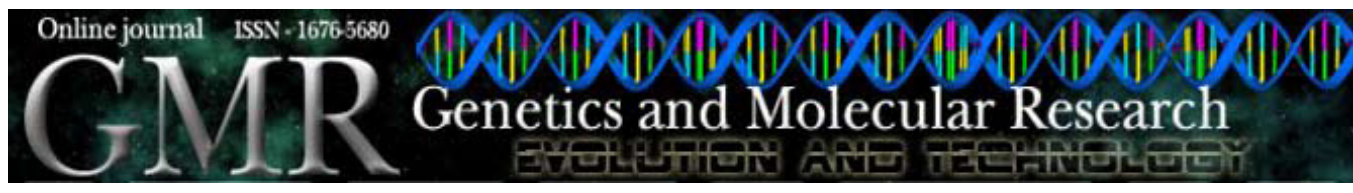

\title{
Genetic characterization of Brazilian strains of Aspergillus flavus using DNA markers
}

\author{
P.P. Batista ${ }^{1}$, J.F. Santos ${ }^{1}$, N.T. Oliveira ${ }^{2}$, A.P.D. Pires ${ }^{2}$, C.M.S. Motta ${ }^{2}$ and \\ E.A. Luna-Alves Lima ${ }^{2}$ \\ ${ }^{1}$ Departamento de Genética, Universidade Federal de Pernambuco, \\ Recife, PE, Brasil \\ ${ }^{2}$ Departamento de Micologia, Universidade Federal de Pernambuco, \\ Recife, PE, Brasil
}

Corresponding author: E.A. Luna-Alves Lima

E-mail: ealal@bol.com.br

Genet. Mol. Res. 7 (3): 706-717 (2008)

Received December 5, 2007

Accepted June 27, 2008

Published August 5, 2008

\begin{abstract}
The Aspergillus genus belongs to a filamentous fungal group characterized by wide dispersion in the environment. Some species are associated with diseases, especially in immunocompromised patients, while others are of economical importance due to aflatoxin production or biotechnological applications. Its species identification is nowadays performed by traditional techniques combined with molecular markers, resulting in a higher efficiency of isolate characterization. In the present study, internal transcribed spacer, inter-simple sequence repeats (ISSR), and random amplified polymorphic DNA (RAPD) molecular markers were used, with the aim of genetically characterizing strains of Aspergillus flavus and strains of other species of the A. flavus group. High genetic diversity was revealed by RAPD and by ISSR, in which the use of the (GACA) $)_{4}$ primer yielded a higher diversity than with the $(\mathrm{GTG})_{5}$ primer, although the latter showed a characteristic banding profile for each species. These data were used to create a similarity matrix for the construction of dendrograms by means of the UPGMA method. The ISSR and RAPD profiles showed that among the strains previously identificated as A. flavus, one should be A. oryzae, one $A$. parasiticus and two $A$. tamarii. On the other hand, a strain previously identified as $A$. parasiticus should be A. flavus. All these strains
\end{abstract}


were retested by traditional methods and their new species identification was confirmed. These results strongly support the need for using molecular markers as an auxiliary tool in differentiating fungal species and strains.

Key words: Aspergillus flavus; Genetic diversity; Molecular markers; Random amplified polymorphic DNA; Internal transcribed spacer; Inter-simple sequence repeats

\section{INTRODUCTION}

The genus Aspergillus belongs to a filamentous fungal group with a wide dispersion in the environment and consists of approximately 200 species (Raper and Fennell, 1977). Several Aspergillus species have received more attention due to biotechnological applications as well as public health problems. Some Aspergillus species are of medical significance, since they are opportunistic pathogens in humans (Verweij et al., 1996; DiazGuerra et al., 2000; Bertout et al., 2001). The genus can be divided into two main groups of species. The first group includes A. flavus, A. parasiticus and A. nomius, species that are aflatoxin producers, and the second group includes A. oryzae, A. sojae and A. tamarii, which are used in the fermenting process in Asian countries (Kumeda and Asao, 2001). However, there are suggestions that $A$. oryzae and $A$. sojae are in fact domesticated strains of A. flavus and A. parasiticus, respectively (Kurtzman et al., 1986).

Traditional methods for species identification are mainly based on morphological parameters, including colony diameter, color and texture, size and texture of conidia and conidiophore structure (Klick, 2002). However, species classification may be difficult due to extensive divergence of morphological characters produced by a high level of genetic variability both inter- and intraspecific (Kumeda and Asao, 1996). Despite intense investigation, the taxonomy of this group of fungi is still highly complex and the genetic techniques to detect the level of polymorphism and similarity among species help minimize the problem. These techniques involve random amplified polymorphic DNA (RAPD) markers, restriction fragment length polymorphism, amplified fragment length polymorphism, inter-simple sequence repeats (ISSR), internal transcribed spacer (ITS), intron, and single-strand conformation polymorphism, which are used as auxiliary tools in traditional methods (Kumeda and Asao, 2001; Dendis et al., 2003). The high degree of genetic variations of nucleotide sequences of the ITS1-5.8S-ITS2 region makes the comparison among Aspergillus species very useful for strain classification and phylogenetic studies (Kumeda and Asao, 1996; Henry et al., 2000). Species identification using ITS markers can be even more reliable than large ribosomal subunit D1-D2 domain sequence analysis (Hinrikson et al., 2005). RAPD markers also significantly contribute to the classification of Aspergillus species (Rath, 2001).

The objective of the present study was to genetically characterize several strains of the Aspergillus flavus group isolated from different sources and deposited at the certified URM Micoteca (Recife, Brazil), using polymerase chain reaction (PCR) amplification of molecular markers. This is the first demonstration of using ISSR markers to characterize Aspergillus species. Unlike ITS, the RAPD and ISSR profiles were of substantial importance as auxiliary tools for the reclassification of strains using traditional methods. 


\section{MATERIAL AND METHODS}

\section{Fungal strains}

The fungal strains used in this study were obtained from the Fungi Culture Collection of the certified Micoteca URM of Departamento de Micologia of Universidade Federal de Pernambuco (Recife, PE, Brazil). A list of the 25 strains of the Aspergillus flavus group studied, along with 5 strains previously classified as A. flavus by traditional methods, including 2 strains of $A$. parasiticus, 2 strains of $A$. oryzae and 1 strain of $A$. sojae, for comparison, are presented in Table 1. A strain of A. niger was also included as outgroup for dendrogram construction. All strains were maintained in PDA (Oxoid) medium at $4^{\circ} \mathrm{C}$.

\begin{tabular}{|c|c|c|c|c|c|}
\hline Strain & URM accession number & Species & Substrate or host & Geographical origin & Year registered \\
\hline 1 & 036 & Aspergillus flavus & - & Pernambuco & 1954 \\
\hline 2 & 221 & Aspergillus flavus & - & Pernambuco & 1957 \\
\hline 3 & 1869 & Aspergillus flavus & Soil & Amapá & 1969 \\
\hline 4 & 2226 & Aspergillus flavus & Bronchial wash & Pernambuco & 1968 \\
\hline 5 & 2487 & Aspergillus flavus & Ground foliage & Pernambuco & 1978 \\
\hline 6 & 2578 & Aspergillus flavus & Soybean seeds & Rio Grande do Sul & 1980 \\
\hline 7 & 2701 & Aspergillus flavus & Contaminant & Brasília & 1981 \\
\hline 8 & 2814 & Aspergillus flavus & Sugar cane remnants & Alagoas & 1985 \\
\hline 9 & 3091 & Aspergillus flavus & Rudigea gardenoides & São Paulo & 1989 \\
\hline 10 & 3426 & Aspergillus flavus & Oats & Pernambuco & 1994 \\
\hline 11 & 3739 & Aspergillus flavus & Water & Pernambuco & 1997 \\
\hline 12 & 4365 & Aspergillus flavus & Soil & Pernambuco & 2001 \\
\hline 13 & 4509 & Aspergillus flavus & Soil & Pernambuco & 2002 \\
\hline 14 & 4526 & Aspergillus flavus & Maize powder & Pernambuco & 2002 \\
\hline 15 & 4541 & Aspergillus flavus & Maize powder & Pernambuco & 2002 \\
\hline 16 & 4709 & Aspergillus flavus & Soil & Pernambuco & 2003 \\
\hline 17 & 4928 & Aspergillus flavus & Soil & Pernambuco & 2005 \\
\hline 18 & 4933 & Aspergillus parasiticus & Soil & Pernambuco & 2005 \\
\hline 19 & 4999 & Aspergillus flavus & Tea & Pernambuco & 2005 \\
\hline 20 & 5167 & Aspergillus flavus & Human skin & Rio de Janeiro & 2005 \\
\hline 21 & 648 & Aspergillus flavus & Ear secretion & Pernambuco & 1956 \\
\hline 22 & 433 & Aspergillus oryzae & Air & Bahia & 1955 \\
\hline 23 & 951 & Aspergillus sojae & - & Japan & 1957 \\
\hline 24 & 1873 & Aspergillus oryzae & Soil & Amapá & 1873 \\
\hline 25 & 5119 & Aspergillus parasiticus & Soil & Pernambuco & 2005 \\
\hline 26 & 5162 & Aspergillus niger & Mortar & Pernambuco & 2005 \\
\hline
\end{tabular}

\section{Mycelial growth and DNA extraction}

Conidia from each strain were suspended in $3 \mathrm{~mL} 0.1(\mathrm{v} / \mathrm{v})$ Tween 80 solution and transferred to Ehrlenmeyer flasks with $100 \mathrm{~mL}$ Czapeck liquid medium. After inoculation, the flasks were maintained at $250 \mathrm{rpm}$ under agitation at room temperature $\left( \pm 28^{\circ} \mathrm{C}\right)$ for $96 \mathrm{~h}$ to obtain mycelial growth. Mycelia were collected by vacuum filtration, washed with distilled water and stored at $-20^{\circ} \mathrm{C}$. DNA extraction was performed according to Raeder and Broda 
(1985), resuspended in TE buffer and kept at $-20^{\circ} \mathrm{C}$ until use. All PCR amplifications were performed in a Techne TC-512 thermocycler (Analitica).

\section{ITS region of rDNA amplification}

The PCR mixtures were made to a final volume of $50 \mu \mathrm{L}$, containing reaction buffer ( 20 $\mathrm{mM}$ Tris- $\mathrm{HCl}, \mathrm{pH} 8.4,50 \mathrm{mM} \mathrm{KCl}), 1.5 \mathrm{mM} \mathrm{MgCl}, 0.2 \mathrm{mM}$ dNTP, $12.5 \mathrm{mM}$ of each primer, ITS4 (5'-TCCTCCGCTTATTGATATGC-3') and ITS5 (5'-GGAAGTAAAAGTCGTAACAA-3'), 1.25 U Taq DNA polymerase (Invitrogen Life Technologies) and 50 ng genomic DNA (White et al., 1990). Amplification consisted of an initial denaturation step at $95^{\circ} \mathrm{C}$ for $4 \mathrm{~min}$ followed by 40 cycles of denaturation at $92^{\circ} \mathrm{C}$ for $1 \mathrm{~min}$, annealing at $51.3^{\circ} \mathrm{C}$ for $1 \mathrm{~min}$ and amplification at $72^{\circ} \mathrm{C}$ for $2 \mathrm{~min}$, with a final extension step at $72^{\circ} \mathrm{C}$ for $5 \mathrm{~min}$. Amplification products for the ITS locus were separated on a $0.8 \%$ agarose gel by electrophoresis at $3 \mathrm{~V} \mathrm{~cm}^{-1}$ in $0.5 \mathrm{X}$ TBE buffer (Trisborate EDTA, pH 8.0), using a 100-bp ladder DNA marker (Invitrogen). The gel was incubated with ethidium bromide and visualized and photographed under UV light.

\section{RAPD by PCR}

In order to identify the best primers to establish the RAPD profile, we tested 29 arbitrary oligonucleotides from the OPW, OPA and OPX Kits (Invitrogen), using total DNA from the URM2578 A. flavus strain as template. The 5 primers that gave high band number and best reproducibility, OPA-10 (5'-GTGATCGCAG-3'), OPA-14 (5'-TCTGTGCTGG-3'), OPA-17 (5'-GACCGCTTGT-3'), OPA-20 (5'-GTTGCGATCC-3'), OPW-04 (5'-CAGAAGCGGA-3') and OPW-05 (5'-GGCGGATAAG-3'), were chosen to perform the complete RAPD profile analysis of all strains. The PCR mixtures were made to a final volume of $25 \mu \mathrm{L}$, containing reaction buffer (20 mM Tris-HCl, $\mathrm{pH} 8.4,50 \mathrm{mM} \mathrm{KCl}), 3.4 \mathrm{mM} \mathrm{MgCl} 2,0.25 \mathrm{mM} \mathrm{dNTP}$, $0.4 \mathrm{mM}$ of each primer, $2 \mathrm{U}$ Taq DNA polymerase (Invitrogen Life Technologies) and $25 \mathrm{ng}$ genomic DNA (Williams et al., 1990). Amplification consisted of an initial denaturation step at $92^{\circ} \mathrm{C}$ for $5 \mathrm{~min}$ followed by 40 cycles of denaturation at $92^{\circ} \mathrm{C}$ for $1 \mathrm{~min}$, annealing at $39^{\circ} \mathrm{C}$ for $1.5 \mathrm{~min}$ and amplification at $72^{\circ} \mathrm{C}$ for $2 \mathrm{~min}$, with a final extension at $72^{\circ} \mathrm{C}$ for $5 \mathrm{~min}$. Amplification products of RAPD were separated on a $1.4 \%$ agarose gel by electrophoresis at $3 \mathrm{~V} \mathrm{~cm}^{-1}$ in $0.5 \mathrm{X}$ TBE buffer (Tris-borate EDTA, $\mathrm{pH}$ 8.0), using a 500-bp ladder DNA marker (Invitrogen). The gel was incubated with ethidium bromide and visualized and photographed under UV light.

\section{ISSR by PCR}

PCR amplification of ISSR was performed with $(\mathrm{GTG})_{5}$ and $(\mathrm{GACA})_{4}$ primers. The reaction mixtures were made to a final volume of $25 \mu \mathrm{L}$, containing reaction buffer $(20 \mathrm{mM}$ Tris- $\mathrm{HCl}, \mathrm{pH} 8.4,50 \mathrm{mM} \mathrm{KCl}), 1.5 \mathrm{mM} \mathrm{MgCl}, 0.25 \mathrm{mM}$ dNTP, $0.25 \mathrm{mM}$ of the primer, 1.25 U Taq DNA polymerase (Invitrogen) and 50 ng genomic DNA (Williams et al., 1990). Amplification consisted of an initial denaturation step at $93^{\circ} \mathrm{C}$ for $5 \mathrm{~min}$ followed by 40 cycles of denaturation at $93^{\circ} \mathrm{C}$ for $20 \mathrm{~s}$, annealing at $55^{\circ} \mathrm{C}$ for $45 \mathrm{~s}$ and amplification at $72^{\circ} \mathrm{C}$ for $90 \mathrm{~s}$, with a final extension at $72^{\circ} \mathrm{C}$ for $6 \mathrm{~min}$. The products were separated on $1.4 \%$ agarose gel by electrophoresis at $3 \mathrm{~V} \mathrm{~cm}^{-1}$ in $0.5 \mathrm{X}$ TBE buffer (Tris-borate EDTA, pH 8.0), using a 100-bp 
ladder DNA marker (Invitrogen). The gel was incubated with ethidium bromide and visualized and photographed under UV light.

\section{RESULTS}

\section{ITS amplification products}

Using the ITS4 and ITS5 primers, a unique band of about 600 bp was obtained for all strains of Aspergillus tested (Figure 1), including the A. niger intended to be used as the outgroup for dendrograms.

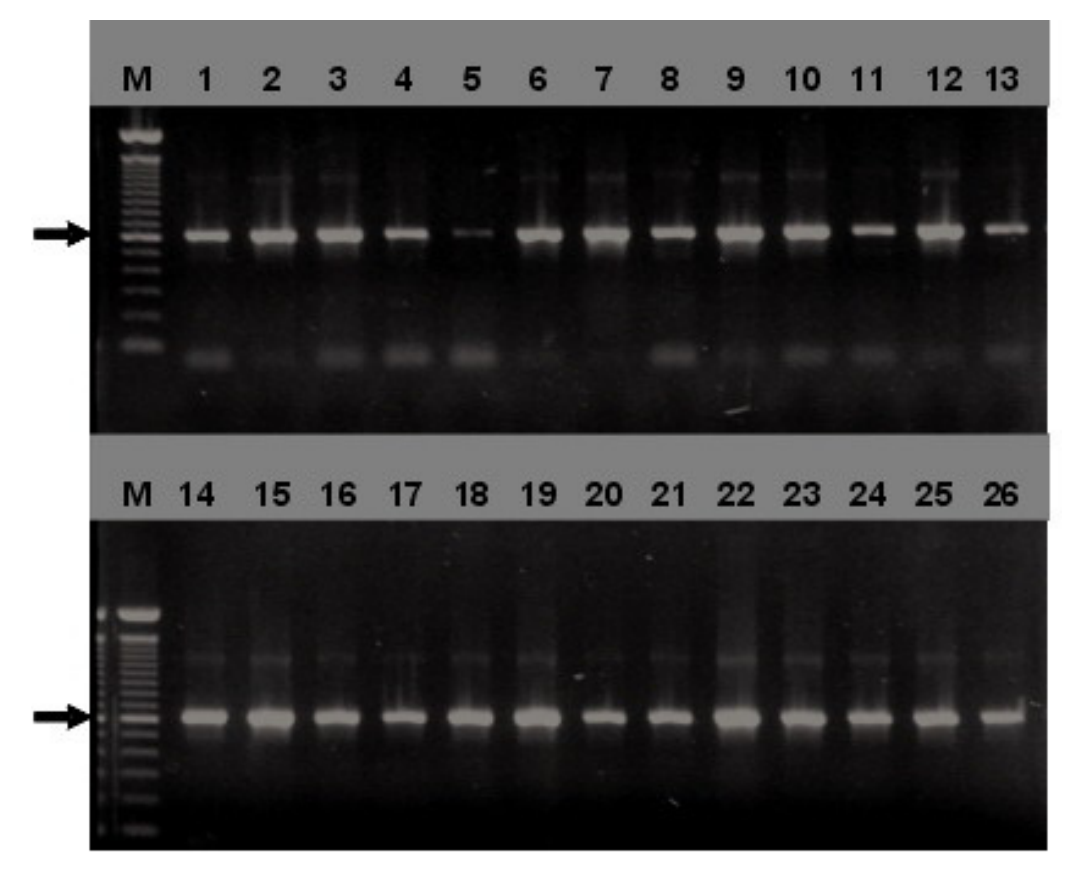

Figure 1. PCR amplification profile of rDNA ITS region of several strains of Aspergillus flavus species group (lanes 1 to 25) and Aspergillus niger (lane 26). Arrows point to a 600-bp band of a 100-bp DNA ladder marker (M).

\section{ISSR amplification}

The amplification profile of ISSR using the (GTG) $)_{5}$ primer showed an average of 12 bands for each of the 20 strains of A. flavus, with size variation between 0.4 and $2.0 \mathrm{~kb}$ (Figure 2). The similarity in banding patterns shared by the majority of strains agreed with their identification as $A$. flavus by classical methods. However, the strain URM2814 previously classified as A. flavus showed a banding pattern similar to that of A. parasiticus, and a new evaluation by conventional techniques confirmed its new identification. On the other hand, the 
strain URM4933 of A. parasiticus displayed a banding pattern similar to that of the A. flavus strains, and reexamination by classical methods confirmed it as $A$. flavus. The banding patterns also indicated that the strains URM3091 and URM648 of $A$. flavus should be $A$. tamarii, and similarly the strain URM4709 of $A$. flavus should be $A$. oryzae. These new identifications were confirmed by reexamination using classical methods.

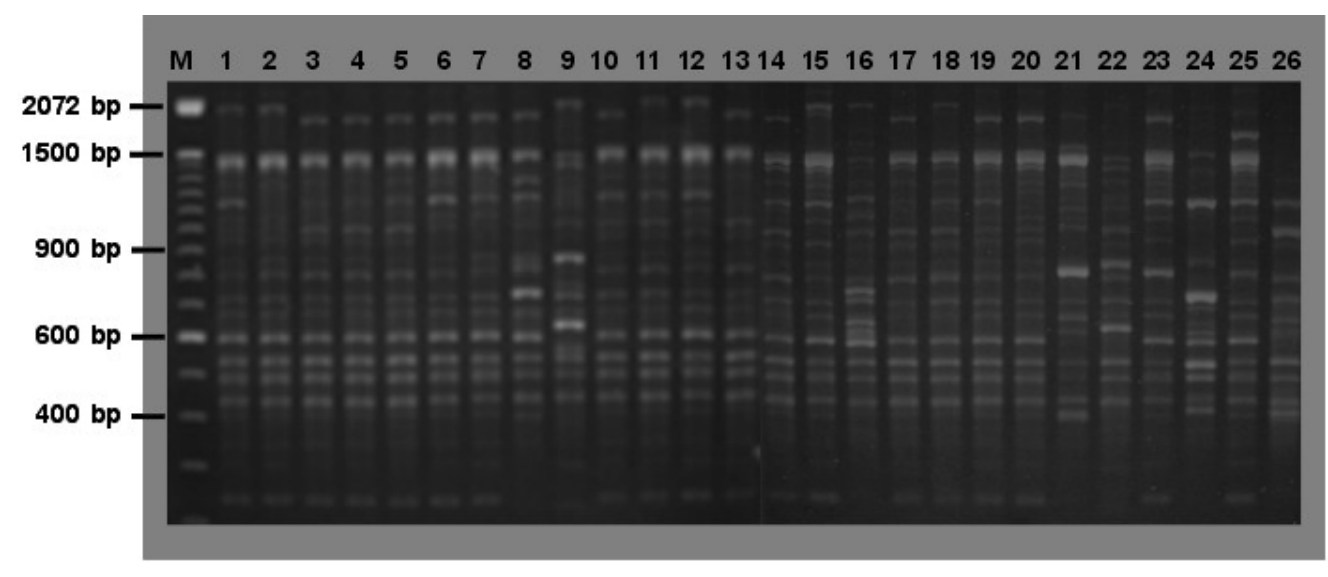

Figure 2. Profile of ISSR amplification by PCR with $(\mathrm{GTG})_{5}$ primer of several strains of Aspergillus flavus species group (lanes 1 to 25) and Aspergillus niger (lane 26). $\mathrm{M}=100$-bp DNA marker.

The ISSR amplification using the (GACA) $)_{4}$ primer produced a variable number of bands in the strains tested, ranging between 0.4 and $2.1 \mathrm{~kb}$ (Figure 3). The variation in banding obtained did not evidence a characteristic profile for A. flavus.

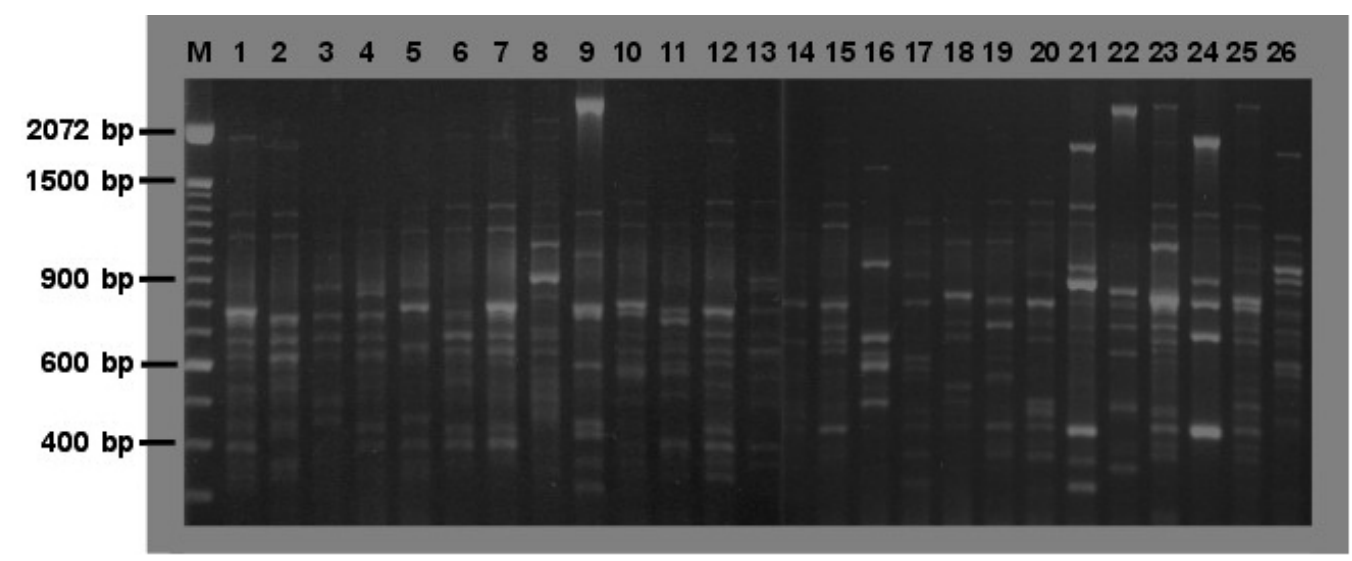

Figure 3. Profile of ISSR amplification by PCR with (GACA) $)_{4}$ primer of several strains of Aspergillus flavus species group (lanes 1 to 25) and Aspergillus niger (lane 26). $\mathrm{M}=100$-bp DNA marker. 


\section{Phenetic analysis}

The dendrogram generated using the similarity matrix produced with the banding patterns obtained with primers (GTG) ${ }_{5}$ and (GACA) $)_{4}$ showed the formation of a main group consisting exclusively of $A$. flavus strains, with a similarity level above $80 \%$, although it was divided into two subgroups, indicating considerable internal variation (Figure 4). The first subgroup included the $A$. flavus strain URM4933 previously misidentified as A. parasiticus. However, the strains URM2814 and URM5167 did not appear in the main group, but had about $60 \%$ similarity with the strain URM951 of $A$. sojae. The strains URM433 and URM1873 of $A$. sojae were joined with a similarity level of $62 \%$. The strains URM648 and URM3091 of A. flavus connected near A. tamarii at $40 \%$ similarity, and the URM5119 was joined at 25\% similarity, near the strain URM3091 and the outgroup strain. The outgroup strain URM5162 of A. niger was correctly placed in the dendrogram.

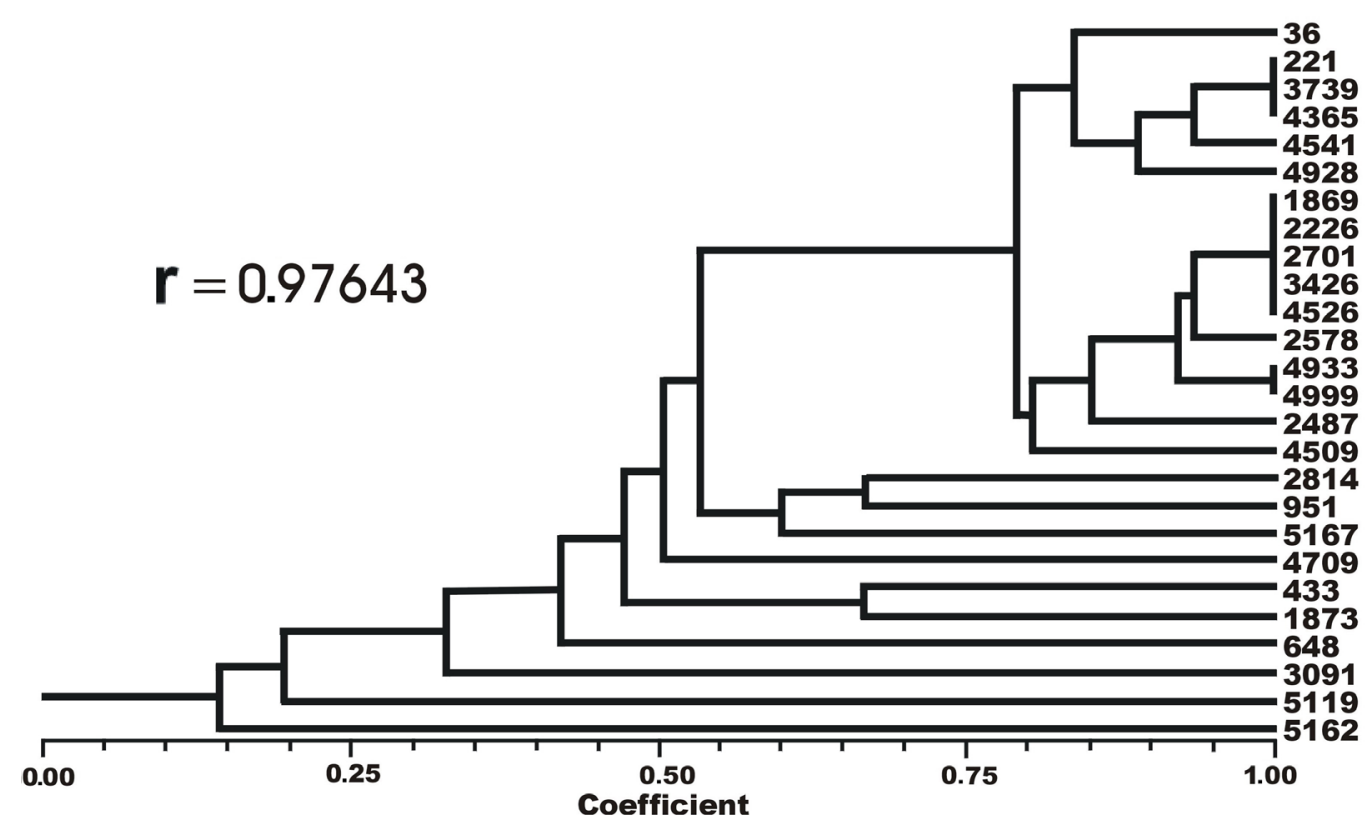

Figure 4. Dendrogram obtained by UPGMA method using Jaccard $(\mathrm{J})$ similarity coefficient calculated from PCR amplification banding of ISSR with $(\mathrm{GTG})_{5}$ and $(\mathrm{GACA})_{4}$ primers of 26 strains of Aspergillus flavus species group. Strain accession numbers in the URM Micoteca are indicated and species classification are shown in Tables 1 and 2.

\section{RAPD marker profiles}

The RAPD banding patterns using the primers OPA-10, OPA-14, OPA-17, OPA-20, OPW04, and OPW-05 were reproducible and displayed high genetic variability among the A. flavus group species. The primer OPW-04 revealed low intraspecific variability and high interspecific variability (Figure 5). The presence or absence of each band obtained with the six chosen RAPD primers was used to create a data matrix used to generate the dendrogram shown in Figure 6. The dendrogram shows the formation of two main groups with $75 \%$ similarity, containing only the $A$. flavus strains, 
including the URM4933 that was suggested above to be A. flavus on the basis of ISSR markers. However, the A. flavus strains URM2814, URM648, URM4709, and URM3091 exhibited low similarity in the RAPD fragment sizes and were not grouped with the other A. flavus strains studied.

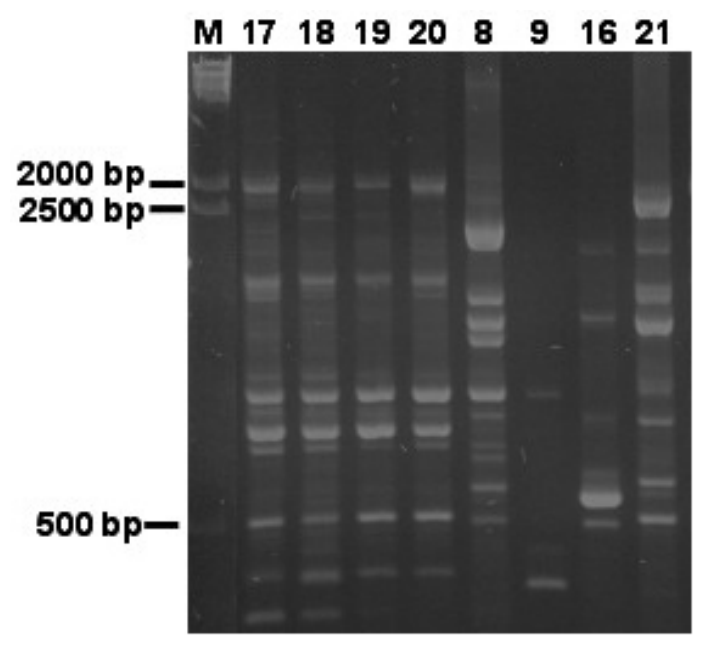

Figure 5. RAPD band profile obtained with OPW-04 of strains of Aspergillus flavus species group. Note the characteristic banding patterns for Aspergillus flavus strains 17, 19 and 20, which include also one Aspergillus parasiticus strain (18), and a second group of Aspergillus flavus strains (8, 9, 16, and 21) with a differential profile. Reclassification of species are as shown in Table 2. $\mathrm{M}=500$-bp DNA marker.

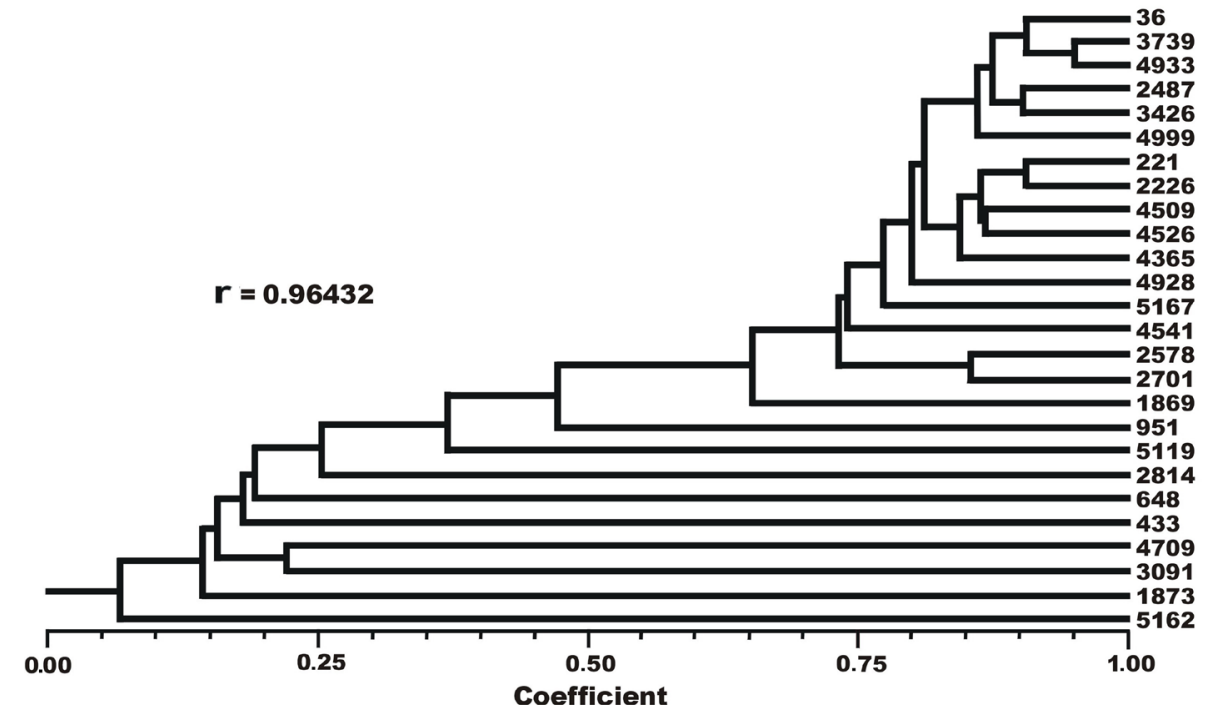

Figure 6. Dendrogram obtained by UPGMA method using Jaccard $(\mathrm{J})$ coefficient calculated from RAPD band profiles obtained with OPA-10, OPA-14, OPA-17, OPA-20, OPW-04, and OPW-05 primers of 26 strains of Aspergillus flavus species group. Strain accession numbers in the URM Micoteca are indicated and species classification are shown in Tables 1 and 2. 


\section{DISCUSSION}

\section{Analysis of ITS of rDNA region}

Amplification of ITS1-5.8S-ITS2 with ITS4 and ITS5 primers produced a unique band of approximately $600 \mathrm{bp}$ for all Aspergillus strains tested here (Figure 1), including the $A$. niger used as outgroup. The fragment size was as expected, since Henry et al. (2000) detected amplification fragments ranging from 565 to $613 \mathrm{bp}$ for different Aspergillus species, which was $595 \mathrm{bp}$ in $A$. flavus. The small variation in band size makes ITS an unreliable parameter for separating Aspergillus species (Hinrikson et al., 2005) and also inadequate for differentiating A. flavus strains, as also demonstrated here. The uniformity of ITS fragment size in several fungal groups makes nucleotide sequencing of ITS fragments necessary to reveal interspecific, and in some cases, also intraspecific variation (Radford et al., 1998; Turenne et al., 1999; Chen et al., 2000; Henry et al., 2000; Hinrikson et al., 2005; Inglis and Tigano, 2006). The analysis of PCR products by single-strand conformation polymorphism and restriction fragment length polymorphism allowed the classification of species in the A. flavus group by Kumeda and Asao (1996), given the high degree of nucleotide variation in the ITS region, undetected by PCR alone. In other fungal groups the ITS region was also very useful in resolving taxonomic difficulties, as demonstrated by Driver et al. (2000) in the taxonomic revision of Metarhizium and by Inglis and Tigano (2006) to reclassify entomopathogenic species of Paecylomyces, previously misidentified by classical methods.

\section{PCR fingerprinting with ISSR microsatellites}

The $(\mathrm{GTG})_{5}$ and $(\mathrm{GACA})_{4}$ primers produced differential amplification products, varying both in size and band intensity. Although (GACA) ${ }_{4}$ revealed higher genetic variability, the number and size of $(\mathrm{GTG})_{5}$ bands were in a characteristic pattern in several strains of A. flavus, even though high interspecific variation was observed. Furthermore, four strains initially classified as A. flavus displayed differential banding patterns, which prompted us to review their taxonomic identification. After a new analysis using classical methods, two strains were reclassified as $A$. tamari, one as A. oryzae and one as A. parasiticus. On the other hand, after this analysis another strain initially classified as $A$. parasiticus that showed an ISSR banding pattern similar to that of A. flavus was reclassified as this species (Table 2). Characteristic banding profiles for $(\mathrm{GTG})_{5}$ were also found in strains of Fusarium solanum (Brasileiro et al., 2004), allowing the discrimination of all isolates. Similarly, Baleiras Couto et al. (1996) and Meyer et al. (1997) also found characteristic ISSR microsatellite profiles in strains of Zygosaccharomyces and Candida, respectively.

\begin{tabular}{|c|c|c|}
\hline Strain & Previous classification & New classification \\
\hline URM648 & Aspergillus flavus & Aspergillus tamarii \\
\hline URM3091 & Aspergillus flavus & Aspergillus tamarii \\
\hline URM4709 & Aspergillus flavus & Aspergillus oryzae \\
\hline URM2814 & Aspergillus flavus & Aspergillus parasiticus \\
\hline URM4933 & Aspergillus parasiticus & Aspergillus flavus \\
\hline
\end{tabular}


The dendrogram produced using the ISSR data showed a main group containing exclusively A. flavus strains, although divided into two subgroups with a similarity level around $80 \%$ (Figure 4). The first subgroup was formed only by A. flavus strains isolated from different substrates in Pernambuco State, which means a high genetic similarity according to the geographical origin. The other A. flavus strains from several origins, including the $A$. parasiticus strain reclassified as $A$. flavus, were placed in the second subgroup. The remaining strains were included in the dendrogram with several levels of similarity, and the A. niger strain was properly positioned as the outgroup, since it is not a species of the A. flavus group. This is the first study to present the use of ISSR microsatellite markers to characterize A. flavus strains. Considering that it does not necessitate previous knowledge of the genome, besides being rapid and reproducible, ISSR analysis can be useful in population genetics, epidemiological surveys and ecological studies of $A$. flavus. Additionally, the (GTG) $)_{5}$ primer can be used to generate unique products from different Aspergillus species that can be converted to a sequence characterized amplified region to help in taxonomic identification.

\section{RAPD analysis}

The six random primers used resulted in an RAPD profile with very different products for each A. flavus strain, providing evidence of its high genetic diversity. The primer OPW-04 produced a similar banding pattern in the A. flavus strains, except for the strains URM2814, URM4709, URM3091, and URM648. The strain URM4933, which was previously identified as A. parasiticus and changed to A. flavus on the basis of ISSR results and new classical evaluation, also had an RAPD banding pattern similar to that of $A$. flavus strains. This was similar to the report of Yuan et al. (1995) who used RAPD to differentiate A. parasiticus and A. sojae, which are morphologically similar species, and who found a strain with a divergent banding profile that was reclassified as A. flavus after reviewing morphological data.

The dendrogram based on RAPD profiles, shown in Figure 6, demonstrated the formation of a main group divided into two subgroups at the $75 \%$ similarity level, composed only of A. flavus strains, including the strain URM4933. This internal subdivision of the main group of A. flavus strains was also observed with ISSR data, as noted above, which makes it likely that this situation represents the high genetic variation among the strains.

However, the A. flavus strains URM2814, URM4709, URM3091, and URM648 showed a low genetic similarity with the main group strains, since they had a different RAPD profile. This is, further, a demonstration of the high intraspecific genetic diversity of A. flavus. The results shown in the present study support the use of RAPD fingerprinting for analyzing A. flavus strains using different primers, as demonstrated before for A. niger (Megnegneau et al., 1993), A. fumigatus (Verweij et al., 1996; Bertout et al., 2001; Bart-Delabesse et al., 2001; Lasker, 2002), A. flavus (Geiser et al., 1998; Diaz-Guerra et al., 2000), A. terreus (Rath et al., 1999), A. nidulans (Rath, 2001), and A. ustus (Rath et al., 2002). It is also true for other species, such as the fumonisin producer Fusarium moniliforme (Jimenez et al., 2000). The use of RAPD has allowed A. flavus strains to be distinguished from other species of the A. flavus group, reinforcing the importance for taxonomic studies, mainly to differentiate strains that show morphological variation in relation to environmental conditions.

In conclusion, the size homogeneity of amplified ITS fragment for all species of the A. flavus group was not effective for species identification. However, the ISSR and RAPD mo- 
lecular markers made possible the detection of inter- and intraspecific genetic variation, which is actually very useful as an auxiliary tool for genetic characterization of A. flavus strains deposited in the URM culture collection. Correct classification is of central interest to large culture collections that provide strains for various research and biotechnological uses.

\section{ACKNOWLEDGMENTS}

The authors thank the Brazilian Agencies CAPES for fellowship to P.P. Batista and $\mathrm{CNPq}$ for financial support.

\section{REFERENCES}

Baleiras Couto MM, Hartog BJ, Huis In't Veld JHJ, Hofstra H, et al. (1996). Identification of spoilage yeasts in a food production chain by microsatellite polymerase chain reaction fingerprinting. Food Microbiol. 13: 59-67.

Bart-Delabesse E, Sarfati J, Debeaupuis JP, van Leeuwen W, et al. (2001). Comparison of restriction fragment length polymorphism, microsatellite length polymorphism, and random amplification of polymorphic DNA analyses for fingerprinting Aspergillus fumigatus isolates. J. Clin. Microbiol. 39: 2683-2686.

Bertout S, Renaud F, Barton R, Symoens F, et al. (2001). Genetic polymorphism of Aspergillus fumigatus in clinical samples from patients with invasive aspergillosis: investigation using multiple typing methods. J. Clin. Microbiol. 39: $1731-1737$.

Brasileiro BTRV, Coimbra MRM, Morais-Junior MA and Oliveira NT (2004). Genetic variability within Fusarium solani species as revealed by PCR-fingerprinting based on PCR markers. Braz. J. Microbiol. 35: 205-210.

Chen YC, Eisner JD, Kattar MM, Rassoulian-Barrett SL, et al. (2000). Identification of medically important yeasts using PCR-based detection of DNA sequence polymorphisms in the internal transcribed spacer 2 region of the rRNA genes. J. Clin. Microbiol. 38: 2302-2310.

Dendis M, Horvath R, Michalek J, Ruzicka F, et al. (2003). PCR-RFLP detection and species identification of fungal pathogens in patients with febrile neutropenia. Clin. Microbiol. Infect. 9: 1191-1202.

Diaz-Guerra TM, Mellado E, Cuenca-Estrella M, Gaztelurrutia L, et al. (2000). Genetic similarity among one Aspergillus flavus strain isolated from a patient who underwent heart surgery and two environmental strains obtained from the operating room. J. Clin. Microbiol. 38: 2419-2422.

Driver F, Milner RJ and Trueman JWH (2000). A taxonomic revision of Metarhizium based on a phylogenetic analysis of rDNA sequence data. Mycol. Res. 104: 134-150.

Geiser DM, Pitt JI and Taylor JW (1998). Cryptic speciation and recombination in the aflatoxin-producing fungus Aspergillus flavus. Proc. Natl. Acad. Sci. U. S. A. 95: 388-393.

Henry T, Iwen PC and Hinrichs SH (2000). Identification of Aspergillus species using internal transcribed spacer regions 1 and 2. J. Clin. Microbiol. 38: 1510-1515.

Hinrikson HP, Hurst SF, Lott TJ, Warnock DW, et al. (2005). Assessment of ribosomal large-subunit D1-D2, internal transcribed spacer 1, and internal transcribed spacer 2 regions as targets for molecular identification of medically important Aspergillus species. J. Clin. Microbiol. 43: 2092-2103.

Inglis PW and Tigano MS (2006). Identification and taxonomy of some entomopathogenic Paecilomyces spp. (Ascomycota) isolates using rDNA-ITS sequences. Genet. Mol. Biol. 23: 132-136.

Jimenez M, Rodriguez S, Mateo JJ, Gil JV, et al. (2000). Characterization of Gibberella fujikuroi complex isolates by fumonisin B1 and B2 analysis and by RAPD and restriction analysis of PCR-amplified internal transcribed spacers of ribosomal DNA. Syst. Appl. Microbiol. 23: 546-555.

Klick MA (2002). Identification of Common Aspergillus Species. Centraalbureau voor Schimmelcultures, Utrecht.

Kumeda Y and Asao T (1996). Single-strand conformation polymorphism analysis of PCR-amplified ribosomal DNA internal transcribed spacers to differentiate species of Aspergillus section Flavi. Appl. Environ. Microbiol. 62: 29472952.

Kumeda Y and Asao T (2001). Heteroduplex panel analysis, a novel method for genetic identification of Aspergillus section Flavi strains. Appl. Environ. Microbiol. 67: 4084-4090.

Kurtzman CP, Smiley MJ, Robnett CJ and Wicklow DT (1986). DNA relatedness among wild and domesticated species in the Aspergillus flavus group. Mycologia 78: 955-959.

Lasker BA (2002). Evaluation of performance of four genotypic methods for studying the genetic epidemiology of

Genetics and Molecular Research 7 (3): 706-717 (2008)

CFUNPEC-RP www.funpecrp.com.br 
Aspergillus fumigatus isolates. J. Clin. Microbiol. 40: 2886-2892.

Megnegneau B, Debets F and Hoekstra RF (1993). Genetic variability and relatedness in the complex group of black Aspergilli based on random amplification of polymorphic DNA. Curr. Genet. 23: 323-329.

Meyer W, Latouche GN, Daniel HM, Thanos M, et al. (1997). Identification of pathogenic yeasts of the imperfect genus Candida by polymerase chain reaction fingerprinting. Electrophoresis 18: 1548-1559.

Radford SA, Johnson EM, Leeming JP, Millar MR, et al. (1998). Molecular epidemiological study of Aspergillus fumigatus in a bone marrow transplantation unit by PCR amplification of ribosomal intergenic spacer sequences. $J$. Clin. Microbiol. 36: 1294-1299.

Raeder U and Broda P (1985). Rapid preparation of DNA from filamentous fungi. Lett. Appl. Microbiol. 1: 17-20.

Raper KB and Fennell DI (1977). The genus Aspergillus. Williams and Wilkins Company, Baltimore, Florida.

Rath PM (2001). Phenotypic and genotypic characterization of reference strains of the genus Aspergillus. Mycoses 44: 65-72.

Rath PM, Kamphoff S and Ansorg R (1999). Value of different methods for the characterisation of Aspergillus terreus strains. J. Med. Microbiol. 48: 161-166.

Rath PM, Petermeier K, Verweij PE and Ansorg R (2002). Differentiation of Aspergillus ustus strains by random amplification of polymorphic DNA. J. Clin. Microbiol. 40: 2231-2233.

Turenne CY, Sanche SE, Hoban DJ, Karlowsky JA, et al. (1999). Rapid identification of fungi by using the ITS2 genetic region and an automated fluorescent capillary electrophoresis system. J. Clin. Microbiol. 37: 1846-1851.

Verweij PE, Meis JF, Sarfati J, Hoogkamp-Korstanje JA, et al. (1996). Genotypic characterization of sequential Aspergillus fumigatus isolates from patients with cystic fibrosis. J. Clin. Microbiol. 34: 2595-2597.

White TJ, Bruns T, Lee S and Taylor JW (1990). Amplification and direct sequencing of fungal ribosomal RNA genes for phylogenetics. In: PCR Protocols: A Guide to Methods and Applications (Innis MA, Gelfand DH, Sninsky JJ and White TJ, eds.). Academic Press Inc., New York, 315-322.

Williams JG, Kubelik AR, Livak KJ, Rafalski JA, et al. (1990). DNA polymorphisms amplified by arbitrary primers are useful as genetic markers. Nucleic Acids Res. 18: 6531-6535.

Yuan GF, Liu CS and Chen CC (1995). Differentiation of Aspergillus parasiticus from Aspergillus sojae by random amplification of polymorphic DNA. Appl. Environ. Microbiol. 61: 2384-2387. 